\title{
How do personality features and skills affect entrepreneurship?
}

\author{
Abdolreza Karimpoor Malakshah ${ }^{20}$
}

\begin{abstract}
Current research aimed to review impact of personality and psychological features on entrepreneurship skills of employees. The research has an applied objective where data were gathered in cross-sectional form. Statistical population is all employees in the Tejarat Bank in one of western cities of Iran who are 250 persons. To determine the size of the sample according to Morgan table, 152 people were determined. Sampling method is simple random sampling. Two questionnaires were used to collect data. To measure validity of the questionnaire, formal validity was used and to measure reliability Cronbach Alpha coefficient was used applying SPSS version 19. $R=0 / 860$ was calculated for questionnaire of personality and psychological features and 0/843 was obtained for entrepreneurship skills questionnaire. For data analysis, descriptive and inferential statistics (Kolmogorov-Smirnov test and binomial test) were used. The results of the research indicate that personality and psychological features of employees are effective in their entrepreneurship skills in working place. So, at the end some suggestions were presented for improving entrepreneurial skills of employees.
\end{abstract}

KEY WORDS: Entrepreneurship, Personality Traits, Entrepreneurial Skills, Personality Skills, Employees

JEL: L26, M12

UDC: 005.332:005.322

COBISS.SR-ID 238310924

\footnotetext{
${ }^{20}$ Executive Management, South Tehran Branch, Islamic Azad University (IAU), Tehran, Iran, e-mail:akmalakshah@gmail.com
} 


\section{INTRODUCTION}

Nowadays everybody believes that personality traits, social and cultural goals and environment and investors can influence on features, performance and goals of companies that have been created (Gedsun, 2010). In fact, feature of the approach seeks to identify potential entrepreneurial features through the assessment of the individual's personality traits and motivations (Haas, Lashgarara, 2010). In the mid-1980`s Thomas Begley and David Boyd, reviewed the literature on psychological characteristics of entrepreneurship to achieve the distinction between traditional managers and entrepreneurs. They eventually identified five dimensions (need to make a breakthrough, control center, risk, tolerance for ambiguity and behavior of type A) (Moghimi, 2005). Entrepreneurial is considered a driving engine for economic development, job creation and social reform. In entrepreneurial studies researchers divided factors affecting entrepreneurial behavior into three categories: social, environmental and individual.

Model of social factors considers factors such as personal history, family history, occupational class, the recent experiences of life, growth and environment etc. important. While environmental factors model notices factors such as asset value, tax reduction, indirect merits, opportunity timing in process of job path and impact of market condition, social improvements, social support and economic culture.(Adimo, 2009). On the other hand the model of individual factor which is widely known as the model features, focuses on personality characteristics of entrepreneurs (Garol, State, 2006).

At present, with regard to the role of entrepreneurs in industrial and economic growth and flourishing of countries and also with regard to the issues and problems that exist in terms of economic and industrial development, it is important to promote entrepreneurship and its culture in community (Ardichvili et al., 2003). Considering the material presented, it can be said whether personality and psychological traits affect entrepreneurial skills of Tejarat bank employees or not?

\section{A REVIEW OF THE LITERATURE AND LITERATURE}

Entrepreneurship is a process that happens in various environments during where changes happen in the economic system through innovation of those who react to economic opportunities and this causes establishment of individual and social value. Entrepreneurs do three main activities:

(1) Business

(2) Innovation in product, process, manufacture and market products and services

(3) Employment, growth and national development of (Akbari, 2007).

In fact, empirical researches in European and American countries imply the positive relationship between entrepreneurial activity and economic implications such as economic growth and innovation in such societies (Osterbek et al., 2010). Culture of entrepreneurship at the micro level is reflected in terms of personality characteristics. In an extreme view "Wolf", believes those who have entrepreneurial nature in themselves become entrepreneurs. This highlights the importance of attitudes and personality traits in the development of entrepreneurship (Foba et al., 2007). Significance of this its role in communities is so that economists have considered it motor for economic growth and development of society and scholars have considered managing it the most important factor of prosperity and organization innovation (Behbahani, 2012). The word entrepreneurship has two absolutely different aspects: the positive which implies special and inherent abilities to understand the opportunities. It combines, thinking outside the framework by defining it uniquely for creating new ideas in this world. Negative side, however, considers entrepreneurial an activity that requires time to understand the real impact of it (Fathyan, 2012). 


\section{FEATURES OF ENTREPRENEURS}

There are different definitions about the personality traits of entrepreneurs. We can say that entrepreneurs are people who are creatively establish opportunities for their business. Entrepreneurship is the detection and optimal use of the opportunities. Entrepreneurs make a great effort to achieve the required benefits and to use the opportunities. Entrepreneurs establish value through the provision of goods, services or new ways. Entrepreneurs create optimal networks, financial resources, initiatives, social networking and negotiations. Entrepreneurs are well aware of the way and the reason of their own opportunities and positions. They make capital themselves and this capital is in forms of financial, social and art. Entrepreneurs take risks and have the ability to manage risk. Entrepreneurs are resistant in the face of adversity and problems. Entrepreneurship requires creativity and innovation (Hadizadeh Moghaddam, Rahimi Feel Abadi, 2005). In this case, Ahmed and Pavan (2012) examined the relationship between personality characteristics (locus of control, willingness to be risk-taking, independence and leadership) with the intention of their entrepreneurship. Results showed a significant relationship between the willingness to risk-taking, independence and leadership with entrepreneurial intentions, but there is no relationship between focus of control with entrepreneurial intentions. Akhmyna (2010) investigated the relationship between personality traits and willingness to entrepreneurship. Results showed a significant relationship between personality characteristics and willingness to be entrepreneurial. The findings also showed that the supportive environment moderates this more relationship more. Caliendo et al (2011) conducted a study to examine traits of personality characteristics. The results indicated that risktaking, trust and integrity, independence and foreign role models affect entrepreneurial decision-making. In a study as the study of the effects of personality characteristics on entrepreneurship Pashaei Fakhri et al. (2012) showed that the components required the need for autonomy, creativity, subtlety of mind, risk-taking spirit of invincibility, internal locus of control, pragmatism and tolerance of ambiguity to successfully achieve the target increases rate of entrepreneurship to five times.) In an article entitled "The Effect of personal and environmental factors on entrepreneurial behavior in Kurdistan university students" Ahmadi et al. (2012) reviewed individual factors. The results showed that individual factors have a significant relationship with entrepreneurial characteristics, so that the male students and those who have a good academic position have higher level of sense of achievement, independence and creativity. In an article entitled "Factors affecting the entrepreneurial skills of rural women in Ilam" Lashgarara et al (2011) concluded that a significant relationship exits between personality traits and entrepreneurial skills. In a research Godarzvand Chegini and Khoshtinat (2011) showed a significant relationship between entrepreneurial skills and capabilities with organizational entrepreneurship. In another study the relationship between 5 main features of their character as big five traits was examined with entrepreneurship (Leutner et al., 2014). Our aim is to predict entrepreneurial skills. Five traits are as follows:

Welcoming new experience, conscientiousness, extraversion, agreeableness and the ability to handle challenges. In addition, this article was conducted on measuring abilities and willingness of entrepreneurs whose aim is to estimate level of success of entrepreneurs in terms of personality traits. (Ahmad Oghlo et al., 2011). In this article features referred to in the literature which received more attention were out of focus. 


\section{RESEARCH METHODOLOGY}

Theoretical framework of the current research is based on the model presented by Thomas Begli and David Bvid (1980) who reviewed literature related to psychological features of entrepreneurship. Following is description of each of the factors:

(1) Needs for success: the desire to do the hard work, being superior and doing better than others in order to achieve a sense of personal achievement (Coles, Berwick, 2006).

(2) Internal locus of control: the individual's belief that events of his life are the result of his skills, attributes and behaviors and NOT environmental factors such as luck and fate (Dilmac et al., 2009).

(3) Risk: despite the common perception that entrepreneurs are people with high risk taking, researches have shown that entrepreneurs take risks. Katz D. Reese (1997) has determined that risk taking is related to self-confidence and control center of the communication. This means that people with high self-esteem and internal locus of control have a higher risk taking (Saiei, Musnick, 2010).

(4) Tolerance for ambiguity: it is to accept uncertainty as a part of life, the ability to survive or incomplete knowledge about the environment and willingness to start a stand-alone activity without knowing you will succeed or not (Ahmadpur Dariani, 2010).

(5) Behavior of type A: they are very competitive and are always anxious, and would like to achieve improvement ASAP in the shortest time and somehow being ambitious in achieving success is a feature of them. Of course many do not enjoy recreation much. This means the motivation to do things is in less time (Moghimi, 2005).

\section{RESEARCH HYPOTHESES}

The main hypotheses: personality traits and psychological have an impact on entrepreneurial skills. Hypothesis 1: the need for success affect entrepreneurial skills. Hypothesis 2: internal locus of control has an effect on entrepreneurial skills.

Hypothesis 3: risk taking has an impact on entrepreneurial skills. Hypothesis 4: tolerance has an ambiguity on entrepreneurial skills. Hypothesis 5: Type A behavior has an effect on entrepreneurial skills.

\section{RESEARCH METHODOLOGY}

Research methodology is an applied in terms of purpose, and data were collected in cross sectional form. Statistical population is all the employees in Tejarat Bank of the sample city who are 250 people. So Korjesi and Morgan tables were used to determine sample size and 152 people were estimated according to the table. Sampling was done through simple random method. Data collection tool is a questionnaire that is self-made. The first questionnaire is related to personality traits and psychological variables that had 35 questions. The second variable is for entrepreneurial skills which is composed of 40 questions. To assess the validity of questionnaire, content validity (formal) was used. Questionnaire was shown to professors and experts, they commented on them, then the final questionnaire was developed. Cronbach's alpha coefficient was used for measuring questionnaire reliability of the questionnaire where SPSS v.19 had been applied. Value 0/86 was achieved for personality and psychological traits and 0/843 for entrepreneurship skills questionnaire. Since Cronbach alpha is more than 7.0 it can be 
concluded that questionnaires have high level of reliability. To measure and analyze data collected descriptive statistics was used for demographic descriptive variables and inferential statistics of Kolmogorov-Smirnov tests were used for binomial test.

\section{RESEARCH FINDINGS}

Before you do anything, it needs to be cleared whether research data are normal or not? In the case of normal condition, parametric tests can be used and if the data do not have a normal distribution, then nonparametric tests can be used. Hence, here's assessment of the normal distribution of data research using the Kolmogorov-smirnov test:

$\mathrm{H}_{0}$ : Factor i has normal distribution

$\mathrm{H}_{1}$ : Factor i has normal distribution .

Table 1: Results of Kolmogorov-smirnov test for normal condition of data:

\begin{tabular}{|c|c|c|c|c|}
\hline Variables & Average & $\begin{array}{c}\text { Standard } \\
\text { deviation }\end{array}$ & $\begin{array}{c}\text { Coefficient } \\
\text { K-s }\end{array}$ & Sig. \\
\hline Need to success & $30 / 12$ & $0 / 871$ & $540 / 0$ & $000 / 0$ \\
\hline Inner control center & $18 / 11$ & $0 / 964$ & $21 / 0$ & $001 / 0$ \\
\hline Risk & $45 / 13$ & $0 / 678$ & $320 / 0$ & $000 / 0$ \\
\hline Power to bear ambiguity & $10 / 11$ & $0 / 478$ & $147 / 0$ & $006 / 0$ \\
\hline Behavior type A & $24 / 12$ & $0 / 589$ & $259 / 0$ & $003 / 0$ \\
\hline entrepreneurship skills & $57 / 12$ & $0 / 899$ & $214 / 0$ & $000 / 0$ \\
\hline
\end{tabular}

According to bale (1) it can be stated that since significance level is less than $0 / 05$, zero hypothesis is rejected and hypothesis one is approved. In other words, research data don`t have normal distribution and is not normal. Hence, non-parametric tests are used.

Main hypothesis: personality and psychological traits have an impact on entrepreneurial skills. To assess the impact of personality traits and psychological entrepreneurial skills ratio tests are used, because this variable has not been normal, so if the effect of personality and psychological traits on entrepreneurial skills of employees is significantly larger than average value 3 , then features of personality and psychological will have an impact on entrepreneurial skills and if they are not significantly larger, then personality and psychological personality traits have no effect on entrepreneurial skills.

Table 2: Results of binomial test for measuring the main hypothesis

\begin{tabular}{|l|l|l|l|l||}
\hline Sig. & Ratio of test & Ratio observed & $\mathrm{n}$ & Group \\
\hline \multirow{3}{*}{$0 / 001$} & \multirow{3}{*}{$0 / 50$} & $0 / 38$ & 58 & G 1: no impact \\
\cline { 3 - 5 } & & $0 / 62$ & 94 & G2: with an impact \\
\cline { 3 - 5 } & & $1 / 00$ & 152 & Sum \\
\hline
\end{tabular}

According to the table above because the test significance level $(0.000)$ is less than given quantity $(\alpha=0 / 05)$, the null hypothesis based on personality and psychological traits will not impact on entrepreneurial skills and it is rejected. So, hypothesis one will be accepted. In other words, personality and psychological traits will impact on the entrepreneurial skills of the employees.

Hypothesis 1: need for success will impact on entrepreneurial skills.

To assess effect of the need to success on entrepreneurial skills, test ratio was used, because this variable has not been normal, so if impact of the need for success on the entrepreneurial skills of the employees is significantly larger than average value of 3, need for success skills will have an impact on entrepreneurship and if not the need to succeed have no effect on entrepreneurial skills. 
Table 3: Binomial test to assess the hypothesis 1

\begin{tabular}{||l|l|l|l|l||}
\hline Sig. & Ratio of test & Ratio observed & $\mathrm{n}$ & Group \\
\hline \multirow{3}{*}{$0 / 001$} & \multirow{3}{*}{$0 / 50$} & $0 / 47$ & 72 & G 1: no impact \\
\cline { 3 - 5 } & & $0 / 53$ & 80 & G2: with an impact \\
\cline { 3 - 5 } & & $1 / 00$ & 152 & Sum \\
\hline
\end{tabular}

According to the table above because the test significance level $(0.000)$ is less than given quantity $(=\alpha=0 / 05)$, the null hypothesis based on entrepreneurship skills will not impact on entrepreneurial skills and it is rejected. So, hypothesis one will be accepted. In other words, entrepreneurship skills will impact on the entrepreneurial skills of the employees.

Secondary hypothesis 2: internal focus of control has an effect on entrepreneurial skills.

To assess effect of internal control center on entrepreneurial skills, test ratio was used, because this variable has not been normal, so if impact of internal control center on the entrepreneurial skills of the employees is significantly larger than average value of 3 , internal control center will have an impact on entrepreneurship and if not internal control center will have no effect on entrepreneurial skills

Table 4: Binomial test to assess the hypothesis 2

\begin{tabular}{|l|l|l|l|l||}
\hline Sig. & Ratio of test & Ratio observed & $\mathrm{n}$ & Group \\
\hline \multirow{3}{*}{$0 / 000$} & \multirow{3}{*}{$0 / 50$} & $0 / 42$ & 64 & G 1: no impact \\
\cline { 3 - 5 } & & $0 / 58$ & 88 & G2: with an impact \\
\cline { 3 - 5 } & & $1 / 00$ & 152 & Sum \\
\hline
\end{tabular}

According to the table above because the test significance level (0.000) is less than given quantity $(=\alpha=0 / 05)$, the null hypothesis based on internal control center will not impact on entrepreneurial skills and it is rejected. So, hypothesis one will be accepted. In other words, internal control center will impact $\mathrm{n}$ entrepreneurship skills.

Hypothesis 3: Risk taking has an impact on entrepreneurial skills.

To assess effect risk taking on entrepreneurial skills, test ratio was used, because this variable has not been normal, so if impact of risk taking on the entrepreneurial skills of the employees is significantly larger than average value of 3 , then risk taking will have an impact on entrepreneurship and if not risk taking will have no effect on entrepreneurial skills.

Table 5: Results of binomial tests for measuring secondary hypothesis 2

\begin{tabular}{|l|l|l|l|l||}
\hline Sig. & Ratio of test & Ratio observed & $\mathrm{N}$ & Group \\
\hline \multirow{3}{*}{$0 / 000$} & \multirow{3}{*}{$0 / 50$} & $0 / 37$ & 56 & G 1: no impact \\
\cline { 3 - 5 } & & $0 / 63$ & 96 & G2: with an impact \\
\cline { 3 - 5 } & & $1 / 00$ & 152 & Sum \\
\hline
\end{tabular}

According to the table above because the test significance level (0.000) is less than given quantity $(=\alpha=0 / 05)$, the null hypothesis based on risk taking will not impact on entrepreneurial skills and it is rejected. So, hypothesis one will be accepted. In other words, risk taking will impact on entrepreneurship skills.

Hypothesis 4: tolerance for ambiguity impact on entrepreneurial skills.

To assess effect of tolerance of ambiguity on entrepreneurial skills, test ratio was used, because this variable has not been normal, so if impact of tolerance of ambiguity on the entrepreneurial skills of the employees is significantly larger than average value of 3 , then 
tolerance of ambiguity will have an impact on entrepreneurship and if not tolerance of ambiguity will have no effect on entrepreneurial skills.

Table 6: Results of binomial test for measuring secondary hypothesis 4

\begin{tabular}{|l|l|l|l|l||}
\hline Sig. & Ratio of test & Ratio observed & $\mathrm{n}$ & Group \\
\hline \multirow{3}{*}{$0 / 000$} & \multirow{3}{*}{$0 / 50$} & $0 / 37$ & 56 & G 1: no impact \\
\cline { 3 - 5 } & & $0 / 63$ & 96 & G2: with an impact \\
\cline { 3 - 5 } & & $1 / 00$ & 152 & Sum \\
\hline
\end{tabular}

According to the table above because the test significance level (0.000) is less than given quantity $(=\alpha=0 / 05)$, the null hypothesis based on tolerance of ambiguity will not impact on entrepreneurial skills and it is rejected. So, hypothesis one will be accepted. In other words, tolerance of ambiguity will impact on entrepreneurship skills.

Hypothesis 5: Type A behavior has an effect on entrepreneurial skills.

To assess effect of behavior type A on entrepreneurial skills, test ratio was used, because this variable has not been normal, so if impact of behavior type A on the entrepreneurial skills of the employees is significantly larger than average value of 3 , then behavior type A will have an impact on entrepreneurship and if not behavior type A will have no effect on entrepreneurial skills.

Table 7: Results of binomial test to assess the hypothesis 5

\begin{tabular}{|l|l|l|l|l||}
\hline Sig. & Ratio of test & Ratio observed & $\mathrm{n}$ & Group \\
\hline \multirow{3}{*}{$0 / 000$} & \multirow{3}{*}{$0 / 50$} & $0 / 33$ & 50 & G 1: no impact \\
\cline { 3 - 5 } & & $0 / 67$ & 102 & G2: with an impact \\
\cline { 3 - 5 } & $1 / 00$ & 152 & Sum \\
\hline
\end{tabular}

According to the table above because the test significance level (0.000) is less than given quantity $(=\alpha=0 / 05)$, the null hypothesis based on behavior type A will not impact on entrepreneurial skills and it is rejected. So, hypothesis one will be accepted. In other words, behavior type A will impact on entrepreneurship skills.

\section{DISCUSSION AND CONCLUSION}

This study investigated the effects of personality and psychological characteristics of the entrepreneurial skills of Tejarat bank employees. As the results showed the most important and original research assume that personality traits and psychological impact on entrepreneurial skills, so it was accepted and the alternative hypothesis (H0) was rejected. Also the results of measuring the second first hypothesis showed that H1 hypothesis regarding success on the entrepreneurial skills has an impact and it was accepted and the alternative hypothesis (H0) was rejected. Results of the second secondary hypothesis showed that the hypothesis H1 regarding internal control has an impact on the entrepreneurial skills and it was accepted and the alternative hypothesis (H0) was rejected. Results of measuring the third one showed that hypothesis $\mathrm{H} 1$ regarding risk taking has an effect on entrepreneurship skills and it was accepted and the alternative hypothesis (H0) was rejected. Results of the forth hypothesis showed that $\mathrm{H} 1$ hypothesis is regarding the tolerance of ambiguity impact on the entrepreneurial skills and it was accepted and the alternative hypothesis (H0) was rejected. The results of the fifth hypothesis (last one) showed that $\mathrm{H} 1$ regarding behavior type $\mathrm{A}$ has an impact on entrepreneurial skills and it was accepted and the alternative hypothesis (H0) was rejected.

According to the results of research and analysis of the hypotheses it is proposed to act traits of Tejarat bank employees and other banks as well. 
Enhancing the desire to work in order to promote the achievement of higher standards in employees.

Training and encouraging employees to strengthen the internal control center to attribute success or failure to the person.

It is proposed to strengthen education and entrepreneurial skills of employees.

It is recommended organizations (banks) stress the importance of innovation in employment policies and the personal characteristics and entrepreneurial skills in the employment of people.

\section{REFERENCES}

[1] Adeyemo, A. (2009). Understanding and acquisition of entrepreneurial skills: a pedagogical re-orientation for classroom teacher in science education", J. Turkish science education. , No. 3, 57-65.

[2] Ahmed, F., Shafi'i, g., Mafakheri nia, F. (2012). The effect of environmental factors on individual and entrepreneurial behavior at Kurdistan University, Entrepreneurship Development Journal, forth year, issue 15.

[3] Ahmad, Z., Pawan, F. (2012). The moderating influence of entrepreneurship program experience on the relationship between personality traits and entrepreneurial intention", International Conference on Excellence in Business, Sharma, United Arab Emirates.

[4] Ahmadpur Dariani, M. (2000). Entrepreneurship (definitions, theories, models), First Edition, Tehran: Pardis Publication

[5] Ahmetoglu, G., Leutner, F.,Chamorro-Premuic, T. (2011). EQ-Nomics: Understanding the relationship between individual differences in Trait Emotional Intelligence and entrepreneurship. Journal of Personality and Individual Differences, 51, 1028-1033.

[6] Akbari, k. A. (2007). Development of Entrepreneurship, Tehran: University Jihad Organization.

[7] Ardichvili, A., Cardozo, R. and Ray, S. (2003); "A theory of entrepreneurial opportunity identification and development". J. Business Venturing., No. 18, 105-123.

[8] Bagheri, M., Namazian, M. (2012). Barriers to entrepreneurship in Iran, the localization and strategies of National Conference on entrepreneurship and business management foundation.

[9] Behbahani, P. (2012). Checking the status quo and identifying constraints, Journal of Construction Manager.

[10] Beigi nia, A., Safari, S., Mohammadi, M. (2010). Reviewing effect of the willingness of employees to organizational entrepreneurship-case study, Journal of management and human resources in the petroleum industry, Issue 13, pp. 36-7.

[11] Caliendo, M., Kritikos, A. (2011); "Searching for the entrepreneurial personality: new evidence and avenues for further research", IZA Discussion Paper, No. 5790, 1-12.

[12]Cantillon, Richard (1755), Essai sur la nature du commerce en general. London;MacMillan

[13] Chong, S. and Chen, H. (2009); "A values, skills and knowledge framework for initial teacher preparation programs", Australian Journal of Teacher Education., No. 3, 1-17.

[14] Cools, E. and Broeck, H. (2006); "Hunting the heffalump: can trait and cognitive characteristics predict entrepreneurial orientation?", Working Paper, University Gent, No. 427, 1-29. 
[15]Dilmac, B. and Hamarta, E. and Arslan, C. (2009); "Analyzing the trait anxiety and locus of control of undergraduates in terms of attachment styles", Educational Sciences Theory \& Practice, No. 9, 143-159.

[16] Ebrahimpur, H, Habibian, S,Nikrouz, Z (2011). The role of skills in entrepreneurship, the National Conference on Entrepreneurship, Cooperation and Economic Jihad.

[17]Fatehian, S. (2012). Factors which are effective on institutionalizing innovation, entrepreneurship and business management knowledge-based National Conference.

[18]Foba, T. W. and Villiers, D. D. (2007); "The integration of entrepreneurship into a performance management model", J. Human resource management, No. 2, 1-8.

[19] Gedeon, S. (2010); "What is entrepreneurship?", J. Entrepreneurial Practice Review , No. 3, 16-35.

[20] Goudarzvand, C. M. (2011), "Study of relationship between entrepreneurial skill and organizational entrepreneurship", J. Australian basic and applied sciences., No. 4, 165-172.

[21] Gurol, Y. and Atsan, N. (2006); "Entrepreneurial characteristics amongst university students: Some insights for entrepreneurship education and training in Turkey", Education Training., No. 1, 25-38.

[22] Hadizadeh Moghaddam, A., Rahimi Feel abadi, F. (2005). Entrepreneurship, Tehran: Janan, first edition, p. 23.

[23] Moqimi, S. M. (2005). Jobs in government agencies, Tehran, Farandish Publication.

[24] Haase, H. and Lautenschlager, A. (2010); "The teach ability dilemma of entrepreneurship", International Entrepreneurship and Management Journal, Vol. 6, No. 1.

[25] Lashgarara, F. and Roshani, N. and Omidi Najafabadi, M. (2011); "Influencing factors on entrepreneurial skills of rural woman in Ilam city, Iran", J. African Business Management , No. 14, 5536-5540.

[26] Leutner, F. et al., (2014), The relationship between the entrepreneurial personality and the Big Five personality traits, Personality and Individual Differences, 58-62

[27] Oosterbeek, H. and Praag, M. V. and Ijsselestein, A. (2010); "The impact of entrepreneurship education on entrepreneurship skills and motivation", J. European Economic Review, No. 54, 442-454.

[28] Pashayi Fakhri, K. and Ghanimat, P. and Koopahi, M. and Behnia, S. (2012); "The study of the effect of personality and psychological traits approach on the rate of entrepreneurship", J. Basic Appl. Sci. Res, No. 4, 4159- 4166.

[29] Pour kiani, M., Jamshidi Gohar Rizi (2012). Identifying barriers to entrepreneurship and providing effective remedies, national conference on entrepreneurship and business management foundation.

[30]Sirec, K. and Mocnic, D. (2010); "How entrepreneurs' personal characteristics affect SMES' growth", Original Scientific Papers, No. 1-2, 3-12.

\section{Article history:}

- $\quad$ Received 25 November 2016

- Accepted 14 February 2017 